\title{
Retroviruses and insertional mutagenesis in mice: proviral integration at the Mov 34 locus leads to early embryonic death
}

\author{
Philippe Soriano, Thomas Gridley, and Rudolf Jaenisch \\ Whitehead Institute for Biomedical Research, Cambridge, Massachusetts 02142 USA; and Department of Biology, \\ Massachusetts Institute of Technology, Cambridge, Massachusetts 02139 USA
}

\begin{abstract}
Thirty-four transgenic mouse strains, each carrying a single proviral insert, were generated by infection of preimplantation and postimplantation embryos with retroviruses. Animals homozygous for proviral integrations were derived for all strains with the exception of Mov 24, where the provirus is inserted on the $Y$ chromosome, and Mov 34. Embryos homozygous at the Mov 34 locus develop normally to the blastocyst stage and die shortly after implantation, indicating that virus integration resulted in a recessive lethal mutation. The provirus and flanking sequences were cloned and the virus was mapped to the 5 ' side of an abundantly and ubiquitously transcribed gene. Similar to the previously derived Mov 13 mutation, proviral integration at the Mov 34 locus interferes with the expression of the adjacent gene. These and our previous results indicate that of a total of 48 proviral integrations in the germ line, two resulted in transgenic mouse strains with recessive lethal mutations.
\end{abstract}

[Key Words: Lethal mutations; insertional mutagenesis; retroviruses; embryonic development]

Received February 20, 1987; revised version received and accepted April 2, 1987.

The analysis of mechanisms that control mammalian embryogenesis is hampered by the lack of molecularly defined mutants that affect developmental processes. The experimental generation of insertional mutations that interfere with mouse development is attractive because this approach mutates and tags a gene at the same time, and the tag allows the molecular cloning of the mutated gene. The use of transposable elements for the generation of insertional mutants has been well documented in prokaryotes, yeast, Drosophila, and plants.

In mammals, both the insertion of retroviruses into the germ line by viral infection of mouse embryos (Jaenisch 1976) and of recombinant DNA by microinjection into the zygote (for review, see Palmiter and Brinster 1986) have been successful in generating transgenic mouse strains that carry early embryonic lethal (Jaenisch et al. 1983; Wagner et al. 1983; Mark et al. 1985) or later-acting (Palmiter et al. 1984; Woychik et al. 1985; Overbeek et al. 1986/ mutations. Furthermore, a spontaneous coat color mutation has been shown to be caused by insertion of an endogenous retrovirus (Jenkins et al. 1981). In Mov 13 mice, the most extensively studied transgenic mutant mouse strain to date, insertion of a Moloney murine leukemia virus (Mo-MLV) genome leads to a recessive mutation which causes death of homozygous embryos at midgestation (Jaenisch et al. 1983). Subsequent studies showed that the provirus had integrated into the first intron of the $\alpha 1$ (I) collagen gene
(Harbers et al. 1984), resulting in a complete block of transcription (Schnieke et al. 1983; Hartung et al. 1986). The Mov 13 mutant strain has been useful for analyzing the role of type I collagen in disease (Löhler et al. 1984; Schnieke et al. 1987) as well as in normal morphogenesis during mammalian development (Kratochwil et al. 1986).

In our previous experiments, the Mov 13 strain was the only mutant obtained from a total of 13 transgenic mouse strains carrying a retroviral genome in the germ line (Jaenisch et al. 1983). In the present work, we have analyzed 34 additional transgenic mouse strains derived by exposing either preimplantation or postimplantation mouse embryos to infectious virus. To determine the frequency of insertional mutations generated by retroviruses, we intercrossed animals heterozygous at individual proviral loci. For 32 strains, homozygous offspring were obtained, and no recognizable mutant phenotypes due to the respective proviral insertions were observed. In the Mov 24 strain, homozygous embryos were not obtained because the provirus has inserted on the Y chromosome. Embryos homozygous at the Mov 34 locus die soon after implantation, indicating that the provirus has induced a recessive lethal mutation. We have molecularly cloned the proviral genome and show that the provirus has inserted close to the $5^{\prime}$ side of an ubiquitously and abundantly transcribed gene, the expression of which is affected by the viral insert. 


\section{Results}

Derivation of transgenic strains

A replication-competent retrovirus derived from MoMLV $^{\text {sup }}$ (Reik et al. 1985), containing a bacterial supF gene in each long terminal repeat (LTR), was used to derive transgenic strains by infection of preimplantation (Mov 15-42) or postimplantation embryos (Mov 43-45). The derivation of strains Mov 15-40 has been described previously (Soriano and Jaenisch 1986). The strains Glob 1-3 were produced by infection of preimplantation embryos with recombinant retroviruses containing a human $\beta$-globin gene and have been described (Soriano et al. 1986).

Mov 43-45 were derived by infection of postimplantation SWR/J embryos at day 8 of gestation (Jaenisch 1980). In contrast to the high efficiency of germ line insertion observed in animals derived from infection of preimplantation embryos (Jaenisch et al. 1981; Soriano and Jaenisch 1986), only three out of 157 animals derived from infected postimplantation SWR/J embryos carried a Mo-MLV provirus. These animals were bred to establish the three transgenic strains Mov 43-45. In addition, only one germ line insertion, which led to the establishment of the Mov 13 strain, was obtained when 1271 offspring derived from similarly infected animals from different strain combinations were screened (Jaenisch et al. 1981; P. Soriano, H. Stuhlmann, and H. Weiher, unpubl.). These results suggest that the genetic background of the mice may influence the susceptibility of primordial germ cells to virus infection.
Derivation of mice homozygous for proviral insertions

Mice heterozygous at a particular Mov or Glob locus were mated and the resulting offspring were analyzed by blot hybridization of tail DNA with virus-specific probes. Animals carrying one (heterozygous) or two (homozygous) copies of the viral genome were distinguished by the relative intensity of the hybridizing viral fragments. For strains that develop viremia (Soriano and Jaenisch 1986), it was important to compare the intensities of fragments representing junctions between viral and flanking cellular sequences, because internal fragments derived exclusively from the viral genome may not represent the genotype of the animal but may be due to copies from superinfecting virus. The amount of DNA loaded in each lane was then compared using either the intensity of specific repeated sequence bands seen by ethidium bromide staining of the gels, or by hybridizing the blots with a single-copy probe. An example of such genotyping is shown in Figure 1.

Table 1 summarizes the results obtained from interbreeding the 34 individual strains. For all but two cases, three classes of offspring containing zero, one, or two proviral copies were observed. The frequencies with which these three classes were obtained were generally close to those predicted from Mendelian expectations, and deviations from predicted values are attributed to statistical variation. Homozygous animals were further bred to establish individual mouse strains. This also allowed verification of the inferred genotypes. The Mov 32 and Mov 33 loci are genetically linked (not shown), and

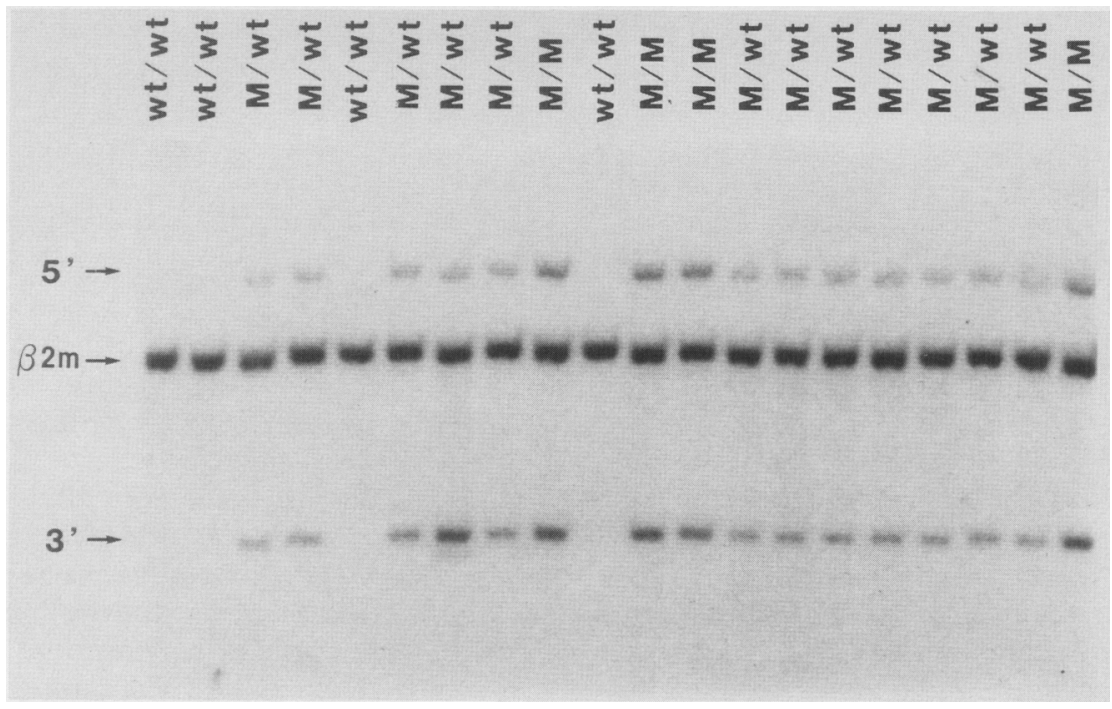

Figure 1. Genotypes of offspring resulting from heterozygous Mov 41 parents. DNA isolated from the tail was digested with KpnI and hybridized with $\pi$ AN7. The larger hybridization band $\left(5^{\prime}\right)$ represents the junction fragment between the $5^{\prime}$ LTR of the provirus and flanking genomic sequence, and the smaller hybridization band $\left(3^{\prime}\right)$ corresponds to an internal fragment at the $3^{\prime}$ end of the provirus. Because the presence of the provirus in the Mov 41 strain leads to the establishment of viremia, internal fragments may also represent additional proviral copies due to superinfecting virus (see seventh lane from the left). The establishment of genotypes was therefore based on the intensity of the junction fragment. The amount of DNA in each lane was compared by including in the hybridization a probe for $\beta-2$ microglobulin $(\beta 2 \mathrm{~m})$. Inferred genotypes are wild-type (wt/wt), heterozygous $(\mathrm{M} / \mathrm{wt})$, and homozygous (M/M). 
Table 1. Genotype of offspring derived from heterozygous parents

\begin{tabular}{|c|c|c|c|c|c|}
\hline Strain & Niremia & $\begin{array}{l}\text { Number of } \\
\text { offspring } \\
\text { screened }\end{array}$ & $\begin{array}{c}\text { Mov/Mov } \\
(\%)\end{array}$ & $\begin{array}{c}\text { Mov/wt } \\
(\%)\end{array}$ & $\begin{array}{c}\mathrm{wt} / \mathrm{wt} \\
|\%|\end{array}$ \\
\hline Mov 15 & + & 72 & 25 & 50 & 25 \\
\hline 16 & + & 33 & 24 & 56 & 21 \\
\hline 17 & + & 71 & 15 & 58 & 27 \\
\hline 18 & + & 71 & 23 & 54 & 23 \\
\hline 19 & + & 26 & 38 & 35 & 27 \\
\hline 20 & + & 9 & 11 & 56 & 33 \\
\hline 21 & + & 19 & 16 & 53 & 31 \\
\hline 22 & + & 29 & 21 & 48 & 31 \\
\hline 23 & - & 17 & 18 & 53 & 29 \\
\hline 24 & + & 120 & 0 & 45 & 55 \\
\hline 25 & + & 20 & 15 & 60 & 25 \\
\hline 26 & - & 20 & 25 & 50 & 25 \\
\hline 27 & + & 21 & 24 & 48 & 28 \\
\hline 28 & + & 12 & 17 & 50 & 33 \\
\hline 29 & - & 25 & 20 & 52 & 28 \\
\hline 30 & - & 30 & 20 & 60 & 20 \\
\hline 31 & + & 29 & 10 & 69 & 21 \\
\hline 32 & ND & 18 & 22 & 61 & 17 \\
\hline 33 & + & 40 & 13 & 67 & 20 \\
\hline 34 & - & 84 & 0 & 67 & 33 \\
\hline 35 & - & 18 & 33 & 45 & 22 \\
\hline 36 & - & 25 & 16 & 68 & 16 \\
\hline 37 & + & 26 & 31 & 50 & 19 \\
\hline 38 & + & 13 & 54 & 38 & 8 \\
\hline 39 & + & 74 & 36 & 38 & 26 \\
\hline 40 & + & 30 & 23 & 54 & 23 \\
\hline 41 & + & 43 & 23 & 54 & 23 \\
\hline 42 & + & 8 & 13 & 37 & 50 \\
\hline 43 & + & 22 & 27 & 59 & 14 \\
\hline 44 & + & 23 & 26 & 56 & 18 \\
\hline 45 & + & 28 & 19 & 60 & 21 \\
\hline Glob 1 & & 23 & 17 & 61 & 22 \\
\hline 2 & & 19 & 31 & 47 & 22 \\
\hline 3 & & 19 & 16 & 58 & 26 \\
\hline \multicolumn{6}{|c|}{ Total lexcept } \\
\hline \multicolumn{2}{|c|}{ Mov 24 and 34 ) } & 933 & 23 & 53 & 24 \\
\hline
\end{tabular}

Animals heterozygous for proviral insertions at Mov or Glob loci were intercrossed, and offspring were analyzed by blot hybridization of tail DNAs as described in the text. All strains were derived by infection of preimplantation embryos except Mov 43-45, which were derived by infection of postimplantation embryos. The percentage of offspring classified on the basis of this analysis as homozygous (Mov/Mov), heterozygous (Mov/wt), or wild type (wt/wt) is indicated. For Mov 24, all resulting offspring containing the provirus were males. (ND) Not determined.

therefore animals carrying both loci were crossed. Proviral integration in the Mov 15 strain occurred in the pseudoautosomal region (Harbers et al. 1986).

In two strains, we failed to obtain homozygous animals. Mov 24 heterozygous males transmitted the provirus only to their sons, indicating that the provirus is carried on the $\mathrm{Y}$ chromosome. No homozygous offspring were obtained from parents heterozygous at the Mov 34 locus, suggesting that proviral insertion at this locus caused a recessive lethal mutation.

Homozygous Mov 34 embryos are arrested early in development

Crosses between parents heterozygous at the Mov 34 locus failed to produce any homozygous animals among
84 offspring analyzed. This result was not only based on comparing the intensity of proviral-specific bands, as described above, but was also confirmed when Southern blots were hybridized with a probe derived from cloned sequences flanking the proviral insert, which distinguishes qualitatively between the different genotypes (see below, and Fig. 2A). The absence of homozygous offspring suggested, therefore, that insertion of the provirus caused a recessive embryonic lethal mutation.

To determine at what stage of development homozygous Mov 34 embryos were arrested, embryos resulting from double heterozygous crosses were examined between days 8 and 13 of gestation /counting the day of the vaginal plug as day $0 \mid$, and DNA was isolated for genotyping. Table 2 shows the result of this analysis. 



Figure 2. Cloning and restriction map of the Mov 34 locus. $(A)$ DNA from wild-type (lanes $A-C$ ) and heterozygous (lanes $D$ and $E$ ) animals was digested with SstI and analyzed by blot hybridization with probes specific for Mo-MLV or derived from the Mov 34 locus (probe A). (B) Restriction map of the Mov 34 locus. Restriction sites for EcoRI (E), BamHI (B), and SstI (S) are indicated. BamHl sites in the provirus are not shown. White boxes represent the viral LTRs, and black boxes the supF gene. Probe A is a 850-bp KpnI-EcoRI fragment and probe B is a 4.8-kb HindIII-BglII fragment. Sequences hybridizing to the cDNA clone C2 are indicated. Arrows represent the orientation of the proviral genome and the direction of transcription of the Mov 34 locus gene.

Embryos were either of wild-type or heterozygous genotype, while the homozygous class of offspring was missing. In addition to these normal-appearing embryos, one-quarter of the implantation sites contained resorbed embryos. The high percentage of conceptuses (embryonic and decidual tissue) with resorbed embryos was seen only when both parents were heterozygous at the Mov 34 locus and was not detected when heterozygous or wild-type animals were mated with wild-type animals. This result suggested that the abnormal conceptuses represented homozygous embryos that had implanted in the uterus but had failed to develop further. To test for normal development at the preimplantation stage, embryos were isolated at the four- to eight-cell stage and cultured in vitro. The same fraction of embryos derived from double heterozygous crosses or from control matings developed to the blastocyst stage (Table
3). This result indicated that homozygous embryos develop normally to the blastocyst stage and die prior to day 8 of gestation. To determine more precisely the time of death, egg cylinder-stage embryos were examined at day 6.5 of gestation. This revealed that about onequarter of the conceptuses contained resorbed embryos or lacked embryos (Table 4). A detailed histological analysis of the resorbed embryos has not yet been performed. These results suggested that homozygous Mov 34 embryos develop normally to the blastocyst stage, implant into the uterus, and die shortly thereafter, before reaching the egg cylinder stage.

\section{Molecular cloning of the Mov 34 locus}

To analyze the nature of the mutation at the Mov 34 locus, a 12-kb EcoRI fragment containing the provirus and flanking cellular sequences was cloned in $\lambda$ Charon

Table 2. Genotype of offspring or embryos derived from heterozygous Mov 34 parents

\begin{tabular}{|c|c|c|c|c|}
\hline Parents & $\mathrm{wt} / \mathrm{wt}$ & Mov/wt & Mov/Mov & $\begin{array}{l}\text { Resorbed } \\
\text { conceptuses }\end{array}$ \\
\hline $\begin{array}{l}q \text { Mov } / \text { wt } \times \delta \text { Mov } / \mathrm{wt} \\
\text { (adult offspring) }\end{array}$ & $\begin{array}{l}28 / 84 \\
(33 \%)\end{array}$ & $\begin{array}{l}56 / 84 \\
(67 \%)\end{array}$ & $0 / 84$ & - \\
\hline $\begin{array}{l}9 \text { Mov/wt } \times \text { o Mov/wt } \\
(\text { embryos day } 8-13 \mid\end{array}$ & $\begin{array}{l}37 / 130 \\
(29 \%)\end{array}$ & $\begin{array}{l}64 / 130 \\
(49 \%)\end{array}$ & $0 / 130$ & $\begin{array}{l}29 / 130 \\
(22 \%)\end{array}$ \\
\hline $\begin{array}{l}q \mathrm{wt} / \mathrm{wt} \times \delta \mathrm{Mov} / \mathrm{wt} \\
\{\mathrm{embryos} \text { day } 9) \\
q \mathrm{wt} / \mathrm{wt} \times \mathrm{wt}^{0} / \mathrm{wt}\end{array}$ & - & - & - & $0 / 54$ \\
\hline (embryos day 9) & - & - & - & $0 / 136$ \\
\hline
\end{tabular}

The genotypes of adult offspring or embryos was determined by blot analysis of tail DNAs or embryonic or placental DNAs as described in the text. 
Table 3. In vitro development of Mov 34 preimplantation embryos

\begin{tabular}{lccc}
\hline & $\begin{array}{c}\text { Number of } \\
\text { embryos } \\
\text { pumber of }\end{array}$ & $\begin{array}{c}\text { Number of } \\
\text { isolated } \\
\text { embryos } \\
\text { developing to } \\
\text { blastocyst }\end{array}$ \\
\hline$\$ \mathrm{Mov} / \mathrm{wt} \times \delta \mathrm{Mov} / \mathrm{wt}$ & 4 & 90 & $84(93 \%)$ \\
$\$ \mathrm{wt} / \mathrm{wt} \times \delta \mathrm{Mov} / \mathrm{wt}$ & 6 & 155 & $145(93 \%)$ \\
\hline
\end{tabular}

Preimplantation embryos were isolated at the 4- to 8-cell stage and allowed to develop in vitro for 2 days. The percentage of embryos forming blastocysts is indicated.

Table 4. Development of Mov 34 embryos to the egg cylinder stage

\begin{tabular}{|c|c|c|c|}
\hline & $\begin{array}{l}\text { Number of } \\
\text { pregnancies }\end{array}$ & $\begin{array}{c}\text { Total } \\
\text { number of } \\
\text { conceptuses }\end{array}$ & $\begin{array}{l}\text { Abnormal } \\
\text { embryos }\end{array}$ \\
\hline \multicolumn{4}{|l|}{$\begin{array}{l}\text { Heterozygous matings } \\
\text { / } 9 \mathrm{Mov} / \mathrm{wt}\end{array}$} \\
\hline$\times \delta$ Mov/wt & 8 & 46 & $12(26 \%)$ \\
\hline \multicolumn{4}{|l|}{ Control matings } \\
\hline $\begin{array}{l}(q \mathrm{wt} / \mathrm{wt} \times \delta \mathrm{Mov} / \mathrm{wt}) \\
(q \mathrm{wt} / \mathrm{wt} \times \delta \mathrm{wt} / \mathrm{wt})\end{array}$ & 6 & 44 & $1(2 \%)$ \\
\hline
\end{tabular}

Embryos were dissected from decidual tissue at the egg cylinder stage as described in experimental procedures. The percentage of implantation sites containing abnormal embryos or containing no embryo is indicated.

4A. The presence of the bacterial supF gene in each LTR permitted selection of phages containing the provirus by plating on a supF- bacterial strain (Reik et al. 1985). Seven of 35 phages thus isolated were shown to contain the $12-\mathrm{kb}$ fragment. Restriction analysis showed that the EcoRI sites were located approximately 140 bases upstream of the $5^{\prime}$ LTR and $2.3 \mathrm{~kb}$ downstream of the $3^{\prime}$ LTR. A DNA fragment (probe A) in the 3 '-flanking sequences contained some repeated sequences but hybridized under stringent conditions to a single band in genomic DNA from wild-type animals. In heterozygous animals, this probe detected an additional band due to the insertion of the provirus (Fig. 2A). This result confirmed that the cloned genomic sequences originated from the proviral integration site, and that flanking probes can be used for accurate genotyping of offspring. Additional flanking sequences were isolated by screening libraries of $\mathrm{A} / \mathrm{J}$ mouse DNA with probe $\mathrm{A}$. These sequences were used to derive a restriction map of the Mov 34 locus (Fig. 2B).

\section{Mov 34 locus expression}

To examine whether the provirus was inserted close to a gene, RNA from different sources was isolated and probed with flanking genomic probes. Initial attempts using probe $\mathrm{A}$ for this purpose were unsuccessful because of the presence of transcribed repeated sequence elements in the probe (not shown). A $0.85-\mathrm{kb}$ unique sequence localized approximately $6 \mathrm{~kb}$ upstream from the
5' LTR did not reveal any transcripts when Northern blots were analyzed. A 4.8-kb unique sequence (probe B) localized 4-9 kb downstream from the $3^{\prime}$ LTR was hybridized to Northern blots and revealed a single abundantly transcribed 1.7-kb RNA with similar intensities in all cell types or tissues analyzed except blood (Fig. $3 \mathrm{~A})$. Analysis of poly(A) ${ }^{+}$RNA showed that this transcript was polyadenylated (not shown). To test whether proviral insertion affected the level of transcription of the gene, RNA from day-10 embryos from the same litter was analyzed (Fig. 3B). The embryos were genotyped by blot analysis of placental DNA. Autoradiograms were scanned with a densitometer and the amount of RNA in each lane was normalized by rehybridizing the blots with an $\alpha$-tubulin probe. This analysis showed the level of the transcript to be 1.57 -fold $( \pm 0.15)$ lower in heterozygous embryos than in wild-type embryos, indicating that the proviral integration interferes with transcription of the gene. A similar analysis on RNA from seven different adult organs showed that the level of this transcript was reduced 2.17-fold $( \pm 0.71)$ in heterozygous animals as compared with wild-type littermates (not shown).

The provirus is inserted on the $5^{\prime}$ side of the gene

A mouse brain cDNA library in $\lambda$ gtll was screened by hybridization with probe $\mathrm{B}$, and one cDNA clone, $\mathrm{C} 2$, was selected for further analysis. C2 contained a 1.45-kb insert which hybridized strongly to the same bands in DNA from wild-type and heterozygous animals as probe $\mathrm{B}$, confirming that this clone represents transcripts from the Mov 34 locus. In addition, C2 hybridized to a lesser extent with an additional band not present in the cloned genomic fragments. Hybridization to cloned genomic sequences showed that the cDNA hybridized only to sequences on the $3^{\prime}$ side of the provirus, located $2.5-7 \mathrm{~kb}$ away from the site of integration (Fig. 2B). C2 hybridized under low stringency to several bands in DNAs from mammals, chicken, and Drosophila, but not to yeast, and under high stringency to fewer bands only in mammals, demonstrating that the gene is evolutionarily conserved (Fig. 4).

The orientation of the transcript was determined by using each strand of the cDNA insert for hybridization to Northern blots (Materials and methods). The transcriptional orientation of the gene was the same as that of the provirus, with its $5^{\prime}$ side toward the provirus (compare Fig. 2). Since the cDNA clone contains $1.45 \mathrm{~kb}$ of the 1.7-kb full-length transcript [including the poly $(\mathrm{A})$ sequences] and hybridizes only to the $3^{\prime}$ side of the insertion, the provinus must have integrated in the $5^{\prime}$ part or on the $5^{\prime}$ side of the transcriptional unit.

\section{Discussion}

Retroviruses were introduced into the germ line by two different infection protocols in an attempt to determine the frequency of insertional mutagenesis. In this and previous work (Jaenisch 1977; Jaenisch et al. 1983), this frequency was determined by breeding heterozygous an- 


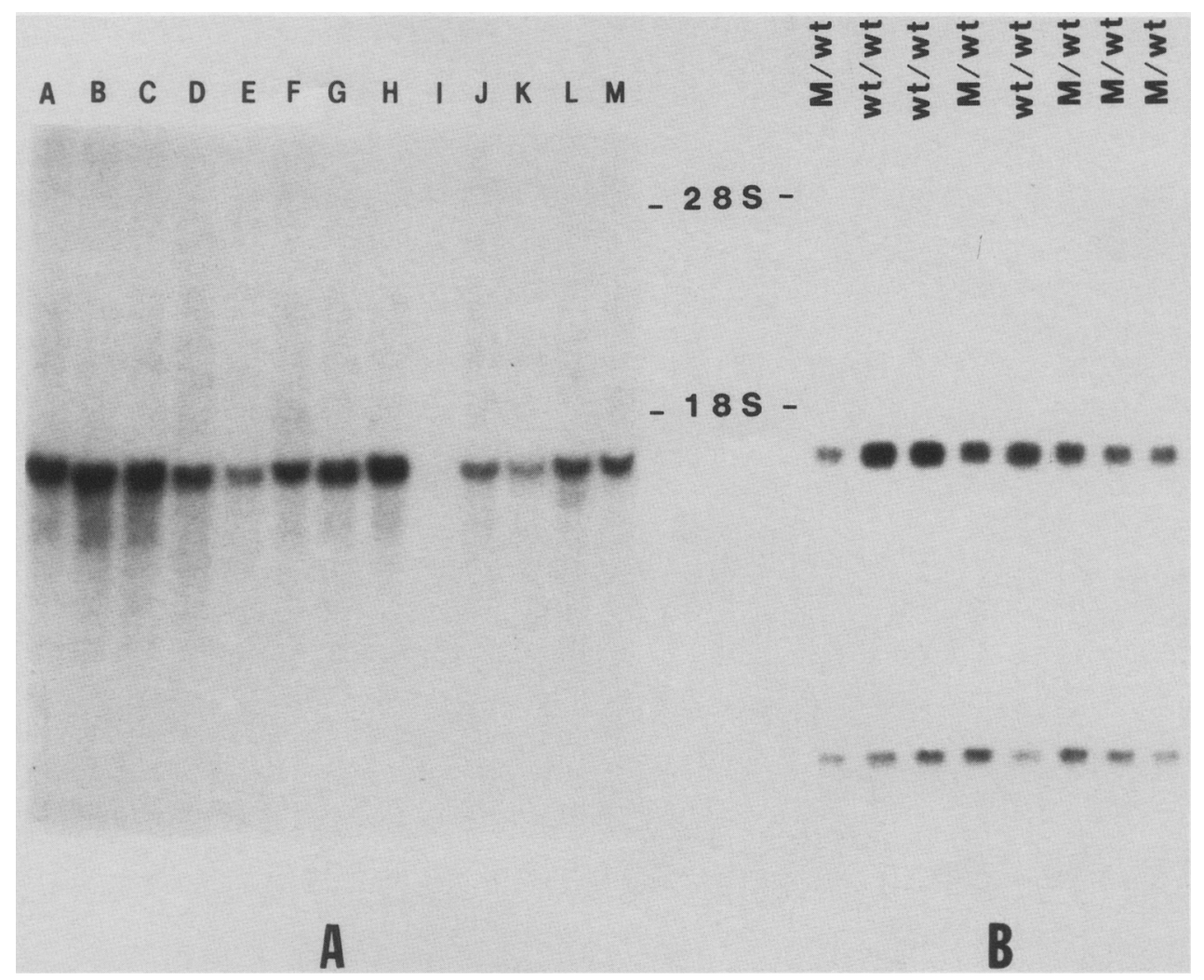

Figure 3. Distribution of $M o v 34$ locus gene transcripts in different tissues and in wild-type and heterozygous embryos. $(A \mid 10 \mu g$ of total RNA from 3 T3 cells (lane $A$ ), F9 cells (lane $B$ ), PCC4 cells (lane $C$ ), a day-10 wild-type embryo (lane $D$ ), a heterozygous day-10 embryo from the same litter (lane $E$ ), placenta (lane $F$ ), two hybridoma lines (lanes $G$ and $H$ ), blood (lane $I$ ), spleen (lane $I$ ), liver (lane $K$ ), brain (lane $L$ ), and kidney (lane $M$ ) were denatured with glyoxal, separated on a $1 \%$ agarose gel, and blot hybridized with probe $B$. The positions of $28 \mathrm{~S}$ and $18 \mathrm{~S}$ ribosomal RNAs are indicated. $(B) 10 \mu \mathrm{g}$ of total RNA from wild-type (wt/wt) and heterozygous $(\mathrm{M} / \mathrm{wt})$ day-10 embryos from the same litter were analyzed by blot hybridization with the cDNA clone C2 (top), and with an $\alpha$-tubulin cDNA probe (bottom; a gift of Ihor Lemischka).

imals and genotyping the offspring. So far, a total of 44 transgenic strains derived from virus-infected preimplantation embryos have been analyzed in this way, and the Mov 34 strain represents the only strain in which proviral insertion resulted in a recessive lethal mutation. The other mutant which has been described previously, the Mov 13 mouse strain, is one of four strains derived from infection of postimplantation embryos (this work and Jaenisch et al. 1983). Our results therefore indicate that two of a total of 48 proviral integrations introduced into the germ line at different stages of embryonic development resulted in transgenic mouse strains with recessive lethal mutations. The overall frequency of insertional mutagenesis may be higher, however, because some strains may carry mutations of a more subtle phenotype that have not been detected in our screen. In addition, dominant lethal mutations would not be detected in our experiments.

The stage at which Mov 34 homozygous embryos die was determined by analyzing embryos derived from double heterozygous matings. Whereas preimplantation embryos developed normally in vitro to blastocysts, about one-quarter of the implantation sites analyzed during later stages contained resorbed embryos. Abnormal development was seen as early as at the egg cylinder stage. At day 8 of gestation, the earliest time at which embryonic material could be isolated in sufficient amount to allow genotyping, no homozygous embryos were found among the normal embryos. This suggested that the resorbed embryos represent the missing class of homozygous offspring. Embryos homozygous for the proviral insertion, therefore, develop normally through the preimplantation stage and die shortly after implantation in the uterus, before developing to the egg cylinder stage.

The provirus was cloned by supF selection, and probes specific for unique flanking sequences were derived. Northern blot analysis revealed that sequences flanking the provinus were abundantly and ubiquitously transcribed. The level of transcription of this gene was reduced in heterozygous offspring as compared with wildtype littermates, suggesting that virus integration interfered with gene transcription. The orientation of the transcript was mapped and mapping indicated that the provirus had inserted toward the $5^{\prime}$ side of sequences present in the mRNA. This may indicate that the pro- 


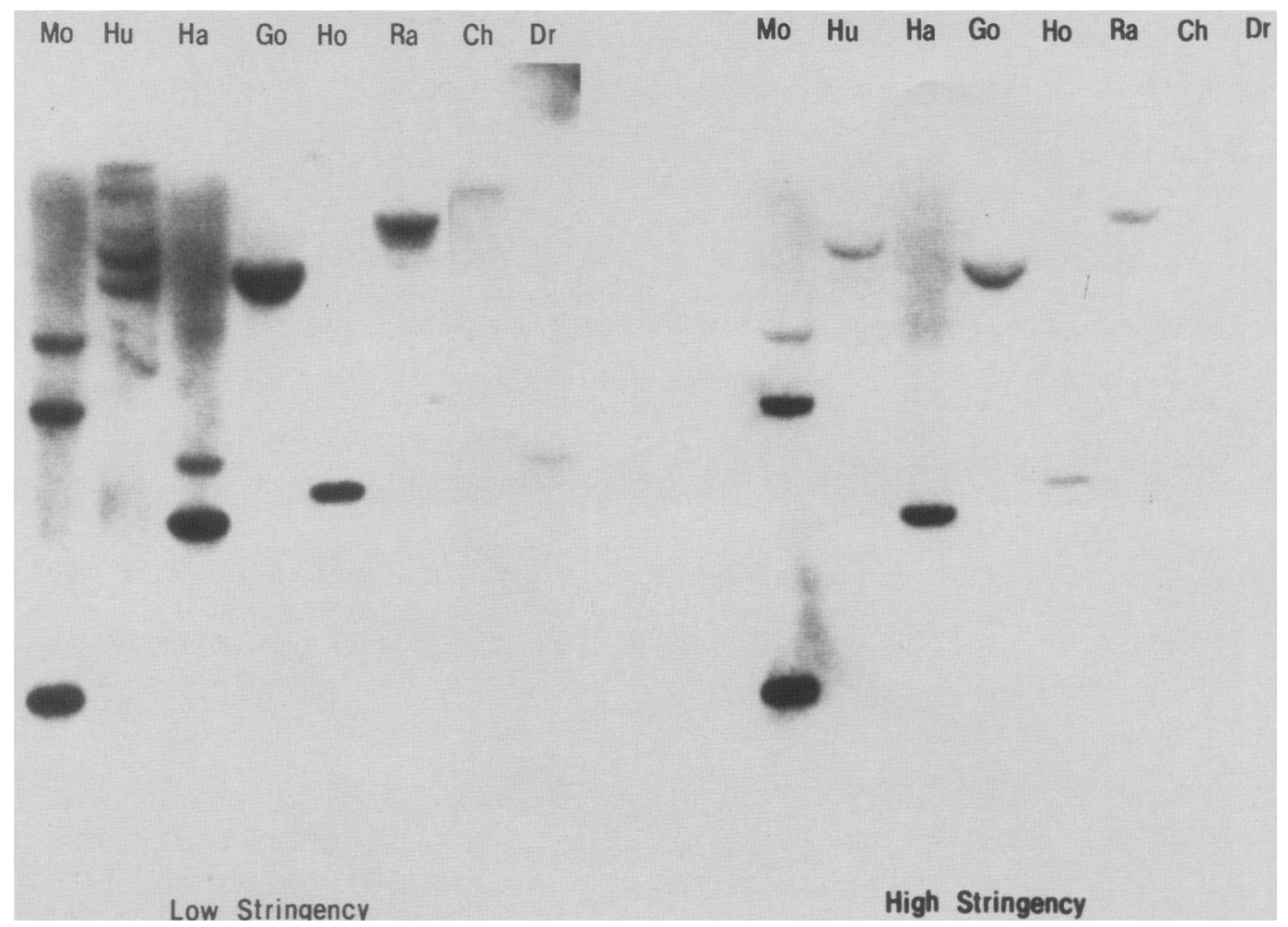

Figure 4. Evolutionary conservation of the Mov 34 gene. DNA (10 $\mu \mathrm{g}$ ) from mouse (Mo), man (Hu), hamster (Ha), goat (Go), horse (Ho), rabbit (Ra), chicken (Ch), and Drosophila (Dr) was digested with EcoRI and hybridized with C2. The filter was washed at low stringency $\left(2 \times \mathrm{SSC}, 65^{\circ} \mathrm{C}\right)$, and then at high stringency $\left(0.1 \times \mathrm{SSC}, 65^{\circ} \mathrm{C}\right)$. Human, goat, horse, and rabbit DNAs were gifts of David Page, and hamster DNA was a gift of Eric Barklis.

virus has inserted near the $5^{\prime}$ end of the gene, or alternatively, that the provirus may be inserted in a large intron. Proviral insertion at the Mov 34 locus may therefore be similar to that at the Mov 13 locus, where the virus has integrated into the first intron at the $5^{\prime}$ end of the $\alpha 1(\mathrm{I})$ collagen gene, leading to interference with the appearance of a DNase hypersensitive site and to de novo methylation of sequences flanking the provirus, as well as inhibition of transcription initiation (Harbers et al. 1984; Breindl et al. 1984; Jähner and Jaenisch 1985; Hartung et al. 1986). A detailed molecular analysis of the Mov 34 mutant allele will be necessary to determine whether the molecular alterations associated with the Mov 13 mutation represent a more general mechanism by which retroviruses induce insertional mutation. It is possible, however, that in addition to the transcript that we have detected, proviral insertion at the Mov 34 locus interferes with transcription of another as yet unidentified gene.

The transcription of the Mov 34 locus gene in most cells, including embryonal carcinoma cells, suggests that this gene is active during early development and continues to be expressed in cells of all tissues of the animal. While the definitive identification of this gene will require a detailed analysis of the cDNA clones, we can speculate on its possible function in early development: (1) The Mov 34 gene product may be present in the oocyte and homozygous embryos develop up to the blastocyst stage due to stored maternal mRNA or protein. Although this is a possibility, experimental evidence has failed so far to detect much stored maternal information beyond early cleavage stages. On the contrary, all available evidence suggests that mammalian development beyond the two-cell stage is crucially dependent on embryonic gene expression (Johnson 1981; Magnusson and Epstein 1981); (2) the gene is expressed in cleavage-stage embryos, but the gene product is only required after implantation; (3) the Mov 34 gene is developmentally regulated and is activated at the time of implantation. A detailed analysis of the Mov 34 gene and the identification of its gene product is likely to provide novel information on gene expression during preimplantation or early postimplantation development, a period of mammalian development about which little is known. Preliminary sequence analysis of the cDNA clone has revealed an open reading frame. Screening of DNA and protein data bases has failed so far to reveal homology to any known protein (T. Gridley, unpubl.). We are presently attempting to derive cell lines homozygous for the proviral insertion from preimplantation embryos, as well as deriving chimeric animals from such cells, to determine if proviral insertion at the Mov 34 locus results in a recessive cell lethal phenotype.

Integration of transposable elements or of recombinant DNA into the genome of a variety of organisms has been shown to result in insertional mutations. Under 
the assumption that insertion of the foreign DNA occurs at random, the frequency of induced mutations would be expected to depend on the amount of coding information that is present in the genome of the organism and that represents the target for insertional mutagenesis. This would predict that an organism with little "excess" of noncoding DNA, such as yeast, would suffer insertional mutations at a much higher frequency than a mammal with its great amount of repetitive and presumably noncoding sequences (see "C value paradox," Lewin 1980). The frequency of lethal mutations induced by insertional mutagenesis has been, however, remarkably similar in yeast, Drosophila, and mice. Random DNA fragments introduced into the yeast genome resulted in $12 \%$ haploid lethal mutations and $14 \%$ transformants with impaired growth, while $70 \%$ of the insertions did not result in a detectable phenotype (Goebl and Petes 1986). Similarly, a screen of spontaneous and unselected insertions of $\mathrm{P}$ elements into the Drosophila genome revealed that between 1 and $18 \%$ of the flies had a mutant phenotype (Simmons et al. 1985; O'Kane and Gehring, pers. comm.). Our results show that two out of 48 proviral insertions into the germ line of mice resulted in a lethal mutant phenotype, while microinjection of recombinant DNA into the pronucleus has induced insertional mutations in approximately $10 \%$ of transgenic mice derived to date (for review, see Palmiter and Brinster 1986). Therefore, these observations indicate that insertional mutations caused by introduction of foreign DNA into the genome of organisms as different as yeast, flies, and mammals occur at comparable frequencies. Three possibilities that are not mutually exclusive can be considered to reconcile the discrepancy between the widely different genome sizes of these species and the apparent similarity in target size for insertional mutagenesis by retroviruses. (1) Retroviruses do not integrate at random but have preferred integration sites near coding sequences. Support for nonrandom integration comes from the analysis of proviral insertion sites in the germ line or in tissue culture cells. In these experiments, a number of unselected proviruses that were analyzed had inserted within a few hundred base pairs of a DNase I hypersensitive site (Conklin and Groudine 1986; Vijaya et al. 1986; Rohdewohld et al. 1987). (2) Integration of a provirus may change the chromosomal domain over a much wider distance, as has been demonstrated for the Mov 13 mutation (Breindl et al. 1984), and therefore may affect the activity of not only the adjacent but also more distant genes. (3) Alternatively, retrovirus insertion in introns may interfere with transcription. These last two possibilities would result in an increase of the target size for mutagenesis beyond that of only adjacent sequences.

Insertional mutations in transgenic mice produced by microinjection of recombinant DNA into the zygote pronucleus have also been observed at a similar, if not higher, frequency to the one we have observed using retroviruses (for review, see Palmiter and Brinster 1986). Evidence is accumulating, however, which suggests that the mechanisms by which these two alternative methods induce mutations may be different. The foreign DNA in transgenic mice derived from zygotes injected with recombinant DNA is frequently found as a tandemly arranged insert and has been shown to induce extensive rearrangements of the flanking host sequences in some instances (Overbeek et al. 1986; Woychik et al. 1986; Covarrubias et al. 1986), complicating identification of the mutated genes. In contrast, no rearrangements of host sequences have been induced by proviral insertions into the germ line of the nine different Mov strains analyzed to date by molecular cloning of the insert (Harbers et al. 1981, 1982, 1984, 1986; Chumakov et al. 1982; and unpubl.). Furthermore, in both mutant strains derived so far, Mov 13 and Mov 34, the gene affected by the provirus was close to the integration site and has been easy to isolate by molecular cloning. While the overall frequency of insertional mutations induced by retroviruses is low, the approach is attractive because once a strain carrying a recessive mutation has been identified by backcrossing, isolation of the mutated gene is unlikely to pose a serious obstacle for the subsequent molecular and biological analysis of the mutant.

\section{Materials and methods}

\section{Derivation and genotyping of transgenic strains}

Mov 15-40 and Glob 1-3 have been described previously (Soriano and Jaenisch 1986; Soriano et al. 1986). Mov 41 and 42, and Mov 43-45 were derived by infection of preimplantation CFW embryos and postimplantation SWR/J embryos, respectively, with Mo-MLVsup virus (Reik et al. 1985) as described previously (Jaenisch 1976; Jaenisch 1980). DNA was isolated from the terminal third of the tail and analyzed by blot hybridization (Jähner and Jaenisch 1985) using $\pi$ AN7 DNA (a gift of Henry Huang) and pXLneo DNA (Soriano et al. 1986) as probes for the Mov and Glob strains, respectively. Because $\pi$ AN7 is prepared from a strain ( $M C 1061$ ) containing additional low-copy-number plasmids (p3 plasmids; Reik et al. 1985), a gel purification step for the isolation of the 900-bp $\pi$ AN7 plasmid was added following density gradient centrifugation. To determine the amount of DNA in each lane, gels were rehybridized with a $\beta-2$ microglobulin probe (a gift of Mike Gilman).

\section{Analysis of mouse embryos}

Preimplantation embryos were isolated on day 2 of gestation (counting the day when vaginal plugs were detected as day 0 ), and cultivated in DMEM supplemented with $10 \%$ fetal calf serum, penicillin, and streptomycin, until they had reached the blastocyst stage. Embryos at the egg cylinder stage were dissected free from decidual tissue in serum-supplemented medium as described (Hogan et al. 1986) and examined visually. DNA was isolated from dissected embryos or placentas at later stages of development as described (Jähner and Jaenisch 1985) and used for genotyping.

\section{Molecular cloning}

A recombinant DNA library was constructed by ligating EcoRIcleaved genomic DNA from a heterozygous Mov 34 animal to the EcoRI site of Charon 4A. About $10^{6}$ recombinant phages, as determined by titration on LE392, were plated on the supF ${ }^{-}$ strain MC1061 (Reik et al. 1985); seven out of 35 plaques that grew on this strain were shown by plaque hybridization to contain the provirus. Genomic DNA segments flanking the provirus were labeled to high specific activity by oligonucleotide 
priming (Feinberg and Vogelstein 1984) and were used to screen libraries of $\mathrm{A} / \mathrm{I}$ mouse DNA constructed by ligation of $\mathrm{Bg} / \mathrm{II}$ fragments to EMBL $3 \mathrm{~A}$ arms, or partial Sau3A digests to EMBL 4 arms (a gift of Lawrence Wysocki), or a mouse brain cDNA library constructed in $\lambda$ gtl 1 (a gift of Yoav Citri). Screening of libraries, subcloning in pGEM-4 (Promega Biotec), and restriction maps were done by established procedures (Maniatis et al. 1982).

\section{RNA blot analysis}

RNA isolation and blot hybridization were as described (Schnieke et al. 1983). All RNA samples were treated with RNase-free DNase (Promega Biotec) prior to gel electrophoresis to minimize background hybridization of genomic probes containing repeated sequences to contaminating DNA.

The orientation of the Mov 34 transcript relative to the provirus was determined by hybridizing each strand of the cDNA clone to Northern blots. First, the cDNA clone was oriented on the genomic map by hybridization of different subfragments. The cDNA insert was then subcloned in pGEM-4 (Promega Biotec), in which the polylinker is flanked by SP6 and T7 promoters. Sequences inserted near the SP6 promoter were proximal to the provirus and the more distal sequences were located near the T7 promoter. Riboprobes were then made using SP6 or T7 RNA polymerases (Promega Biotec), and used for hybridization to Northern blots as described (Melton et al. 1984). The 1.7-kb RNA was detected only following hybridization with the T7 probe, and not with the SP6 probe. Since the T7 probe must be antisense to the $1.7-\mathrm{kb}$ transcript, this result demonstrates that the gene is oriented with the $5^{\prime}$ side toward the provirus.

\section{Acknowledgments}

We thank Heidi Stuhlmann and Hans Weiher for allowing us to cite their unpublished results on infection of postimplantation embryos, Doris Grotkopp and Ruth Curry for excellent technical assistance, Lawrence Wysocki and Yoav Citri for the gift of phage libraries, and our colleagues for their critical comments on the manuscript. T.G. was supported by a postdoctoral fellowship (PF-2645) from the American Cancer Society. This work was supported by grant HD-19105 from the National Institutes of Health, and by grant PO1-CA38497 from the National Cancer Institute.

\section{References}

Breindl, M., K. Harbers, and R. Jaenisch. 1984. Retrovirus-induced lethal mutation in collagen I gene of mice is associated with altered chromatin structure. Cell 38: 9-16.

Chumakov, I.H., H. Stuhlmann, K. Harbers, and R. Jaenisch. 1982. Cloning of two genetically transmitted Moloney leukemia proviral genomes: Correlation between biological activity of the cloned DNA and viral genome activation in the animal. J. Virol. 42: 1088-1098.

Conklin, K.F. and M. Groudine. 1986. Varied interactions between proviruses and adjacent host chromatin. Mol. Cell. Biol. 6: 3999-4007.

Covarrubias, L., Y. Nishida, and B. Mintz. 1986. Early postimplantation embryo lethality due to DNA rearrangements in a transgenic mouse strain. Proc. Natl. Acad. Sci. 83: 60206024.

Feinberg, A.P. and B. Vogelstein. 1984. A technique for radiolabeling DNA restriction fragments to high specific activity. Anal. Biochem. 137: 266-267.

Goebl, M.G. and T.D. Petes. 1986. Most of the yeast genomic sequences are not essential for cell growth and division. Cell 46: $983-992$.

Harbers, K., A. Schnieke, H. Stuhlmann, D. Jähner, and R. Jaenisch. 1981. DNA methylation and gene expression: Endogenous retroviral genome becomes infectious after molecular cloning. Proc. Natl. Acad. Sci. 78: 7609-7613.

Harbers, K., A. Schnieke, H. Stuhlmann, and R. Jaenisch. 1982. Infectivity and structure of molecular clones obtained from two genetically transmitted Moloney leukemia proviral genomes. Nucleic Acids Res. 10: 2521-2537.

Harbers, K., M. Kuehn, H. Delius, and R. Jaenisch. 1984. Insertion of retrovirus into the first intron of $\alpha 1(\mathrm{I})$ collagen gene leads to embryonic lethal mutation in mice. Proc. Natl. Acad. Sci. 81: 1504-1508.

Harbers, K., P. Soriano, U. Müller, and R. Jaenisch. 1986. High frequency of unequal recombination in pseudoautosomal region shown by proviral insertion in transgenic mouse. $\mathrm{Na}$ ture 324: 682-685.

Hartung, S., R. Jaenisch, and M. Breindl. 1986. Retrovirus insertion inactivates mouse $\alpha 1$ (I) collagen gene by blocking initiation of transcription. Nature 320: 365-367.

Hogan, B., F. Costantini, and E. Lacy. 1986. Manipulating the mouse embryo: A laboratory manual. Cold Spring Harbor Laboratory, Cold Spring Harbor, New York.

Jaenisch, R. 1976. Germ line integration and Mendelian transmission of the exogenous Moloney leukemia virus. Proc. Natl. Acad. Sci. 73: 1260-1264.

.1977. Germ line integration of Moloney leukemia virus: Effect of homozygosity at the M-MuLV locus. Cell 12: 691696.

-1980. Retroviruses and embryogenesis: Microinjection of Moloney leukemia virus into midgestation mouse embryos. Cell 19: 181-188.

Jaenisch, R., D. Jähner, P. Nobis, I. Simon, J. Löhler, K. Harbers, and D. Grotkopp. 1981. Chromosomal position and activation of retroviral genomes inserted into the germ line of mice. Cell 24: 519-529.

Jaenisch, R., K. Harbers, A. Schnieke, J. Löhler, I. Chumakov, D. Jähner, D. Grotkopp, and E. Hoffman. 1983. Germline integration of Moloney murine leukemia virus at the Mov 13 locus leads to recessive lethal mutation and early embryonic death. Cell 32: 209-216.

Jähner, D. and R. Jaenisch. 1985. Retrovirus induced de novo methylation of flanking host sequences correlates with gene inactivity. Nature 315: 594-597.

Jähner, D., H. Stuhlmann, C.L. Stewart, K. Harbers, J. Löhler, I. Simon, and R. Jaenisch. 1982. De novo methylation and expression of retroviral genomes during mouse embryogenesis. Nature 298: 623-628.

Jenkins, N.A., N.G. Copeland, B.A. Taylor, and B.K. Lee. 1981. Dilute (d) coat color mutation of DBA/2J mice is associated with the site of integration of an ecotropic MuLV genome. Nature 293: 370-374.

Johnson, M.H. 1981. The molecular and cellular basis of preimplantation mouse development. Biol. Rev. 56: 463-498.

Kratochwil, K., M. Dziadek, J. Löhler, K. Harbers, and R. Jaenisch. 1986. Normal epithelial branching morphogenesis in the absence of collagen I. Dev. Biol. 117: 596-606.

Lewin, B. 1980. Gene expression, vol. 2, pp. 479-502. John Wiley and Sons, New York.

Löhler, J., R. Timpl, and R. Jaenisch. 1984. Embryonic lethal mutation in mouse collagen I gene causes rupture of blood vessels and is associated with erythropoietic and mesenchymal cell death. Cell 38: 597-607.

Magnusson, T. and C.J. Epstein. 1981. Genetic control of very early mammalian development. Biol. Rev. 56: 369-408. 
Maniatis, T., E.F. Fritsch, and J. Sambrook. 1982. Molecular cloning: A laboratory manual. Cold Spring Harbor Laboratory, Cold Spring Harbor, New York.

Mark, W.H., K. Signorelli, and E. Lacy. 1985. An insertional mutation in a transgenic mouse line results in developmental arrest at day 5 of gestation. Cold Spring Harbor Symp. Quant. Biol. 50: 453-463.

Melton, D.A., P.A. Krieg, M.R. Rebagliati, T. Maniatis, K. Zinn, and M.R. Green. 1984. Efficient in vitro synthesis of biologically active RNA and RNA hybridization probes from plasmids containing a bacteriophage SP6 promoter. Nucleic Acids Res. 12: 7035-7056.

Overbeek, P.A., S.P. Lai, K.R. Van Quill, and H. Westphal. 1986. Tissue specific expression in transgenic mice of a fused gene containing RSV terminal sequences. Science 231: 15741577.

Palmiter, R.D. and R.L. Brinster. 1986. Germ line transformation of mice. Annu. Rev. Genet. 20: 465-499.

Palmiter, R.D., T.M. Wilkie, H.Y. Chen, and R.L. Brinster. 1984. Transmission distortion and mosaicism in an unusual transgenic mouse pedigree. Cell 36: 869-877.

Reik, W., H. Weiher, and R. Jaenisch. 1985. Replication-competent Moloney murine leukemia virus carrying a bacterial suppressor tRNA gene: Selective cloning of proviral and flanking host sequences. Proc. Natl. Acad. Sci. 82: 11411145.

Rohdewohld, H., H. Weiher, W. Reik, R. Jaenisch, and M. Breindl. 1987. Retrovirus integration and chromatin structure: Moloney murine leukemia proviral integration sites map near DNase I hypersensitive sites. I. Virol. 61:336343.

Schnieke, A., K. Harbers, and R. Jaenisch. 1983. Embryonic lethal mutation in mice induced by retrovirus insertion into the $\alpha 1(\mathrm{I})$ collagen gene. Nature 304: 315-320.

Schnieke, A., M. Dziadek, J. Bateman, T. Mascara, K. Harbers, R. Gelinas, and R. Jaenisch. 1987. Introduction of the

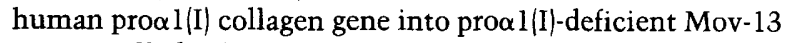
mouse cells leads to formation of functional mouse human hybrid type I collagen. Proc. Natl. Acad. Sci. 84: 764-768.

Simmons, M.J., J.D. Raymond, T.R. Laverty, R.F. Doll, N.C. Raymond, G.J. Kocur, and E.A. Drier. 1985. Chromosomal effects on mutability in the P-M system of hybrid dysgenesis in Drosophila melanogaster. Genetics 111: 869-884.

Soriano, P. and R. Jaenisch. 1986. Retroviruses as probes for mammalian development: Allocation of cells to the somatic and germ cell lineages. Cell 46: 19-29.

Soriano, P., R.D. Cone, R.C. Mulligan, and R. Jaenisch. 1986. Tissue-specific and ectopic expression of genes introduced into transgenic mice by retroviruses. Science 234: 14091413.

Vijaya, S., D.L. Steffen, and H.L. Robinson. 1986. Acceptor sites for retroviral integrations map near DNase I-hypersensitive sites in chromatin. J. Virol. 60: 683-692.

Wagner, E.F., L. Covarrubias, T.A. Stewart, and B. Mintz. 1983. Prenatal lethalities in mice homozygous for human growth gene sequences integrated in the germ line. Cell 35: 647665.

Woychik, R.P., T.A. Stewart, L.G. Davis, P. D'Eustachio, and P. Leder. 1985. An inherited limb deformity created by insertional mutagenesis in a transgenic mouse. Nature 318: 3640. 


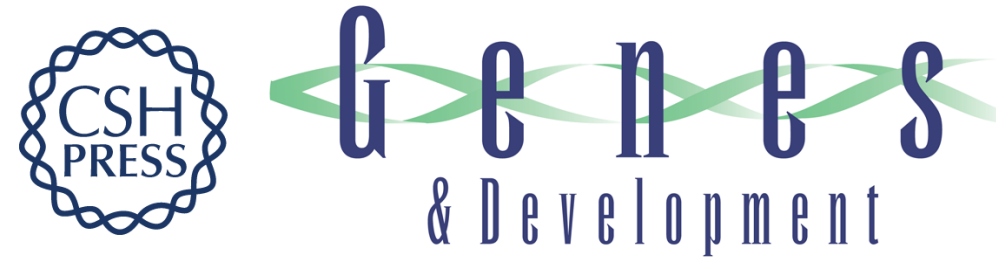

\section{Retroviruses and insertional mutagenesis in mice: proviral integration at the Mov 34 locus leads to early embryonic death.}

P Soriano, T Gridley and R Jaenisch

Genes Dev. 1987, 1:

Access the most recent version at doi:10.1101/gad.1.4.366

References This article cites 38 articles, 14 of which can be accessed free at: http://genesdev.cshlp.org/content/1/4/366.full.html\#ref-list-1

License

Email Alerting

Service

Receive free email alerts when new articles cite this article - sign up in the box at the top right corner of the article or click here.

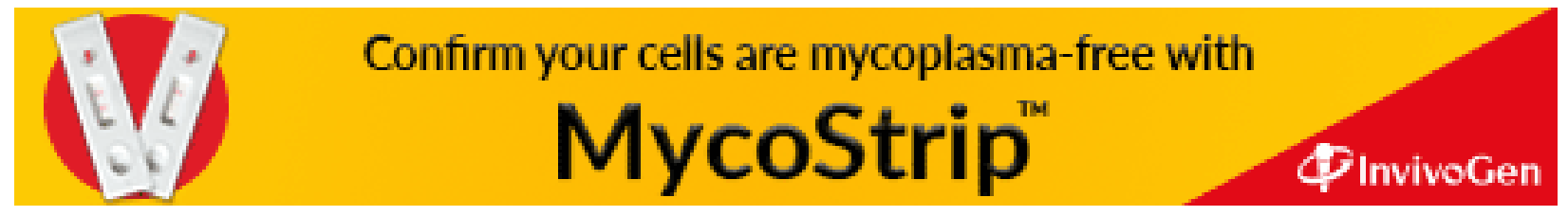

